\title{
Real Time Monitoring of Salinity Gradient and Solar Pond Temperatures
}

\author{
Zaenab Muslimin ${ }^{1 *}$,Agus Siswanto ${ }^{1,2}$, Indar Chaerah Gunadin ${ }^{1}$, and Muhammad Anshar ${ }^{1}$ \\ ${ }^{1}$ Departement of Electrical Engineering Hasanuddin of University \\ ${ }^{2}$ Departement of Electrical Engineering 17 Agustus 1945 Cirebon of University
}

\begin{abstract}
Electric energy is an important factor for human needs, functions as lighting, and various human activities. The large amount of electrical energy needs demands to create various alternative electrical energy. Alternative energy uses renewable energy sources to avoid crisis and energy scarcity. The National Energy Policy (KEN) has encouraged the government and the private sector and the public to use energy effectively and efficiently, and to utilize renewable energy. The direction of national energy policy includes reducing dependence on fossil fuels, specifically petroleum. Utilization of renewable energy is needed for the sustainability of national energy supply and reserves. Indonesia is called a maritime country, because $2 / 3$ of Indonesia's territory is the sea with the longest coastline in the world, which is $\pm 80,791.42 \mathrm{Km}$ and is also called an archipelagic country because it has thousands of islands. This natural situation is a great potential for the development of renewable energy, especially the energy sourced from the sea spread wide and very abundant, namely solar pond. One of the alternative sources of renewable energy sourced from the sea currently not developed in Indonesia is solar ponds, even though Indonesia has a huge geographical potential to develop this technology. There are at least two potential parameters for building a solar pond, first because Indonesia has a tropical climate with a large enough intensity of sun, second because Indonesia is a maritime country surrounded by sea, so the availability of raw water is very abundant. Solar pond is not a new power generation technology. In the history of electricity generation technology in Indonesia, this technology has never been tested and implemented at all. In this study, it has a long-term goal of generating electricity from solar ponds. Solar pond technology is a type of environmentally friendly power plant, based on seawater using sunlight to get the difference in heat in the solar pool so that the thermal layer can be converted into electrical energy. The specific targets, namely data salinity and temperature data on the prototype solar pond have been realized in the form of cylindrical with a height of $1.05 \mathrm{~m}$
\end{abstract}

* Corresponding author: zaenab_muslimin@yahoo.com 
and a diameter of 0.8 meters. Solar pool research, in line with the goal of national transformation as a significant contributor to the benefit of the Indonesian Maritime Continent. In line with the development of electricity generation technology, solar pond technology has never been implemented in Indonesia, so this research is in accordance with the 2016-2020 National Strategic Plan number 51868 / UN4.1 / PR.04 / 2016

\section{Introduction}

The use of fossil fuel energy sources, whose number is very limited and factually is one of the sources of air pollution and the environment of mankind, until now still dominates the fulfilment of world energy needs. The need and enormous dependence on various activities of modern human life can be found in many sectors such as in the world of transportation, industry, government sector and housing sector. This has an impact on the availability and energy security in the future which triggers fears that fossil fuel-based energy sources will run out in the next few decades. The Ministry of Energy and Mineral Resources (ESDM) revealed, if a country still relied on fossil energy it would enter an era of energy crisis. Because, this type of resource cannot be renewed and will eventually run out. Director of the ESDM Ministry's New and Renewable Energy Variety Marice Hutapea said that Indonesia had entered the era of the fossil energy crisis. The only way out of this problem is to develop new and renewable or non-fossil energy. Research on the potential of renewable energy in Indonesia has been carried out [1-4] which includes biodiesel, wind turbine, potential irrigation.

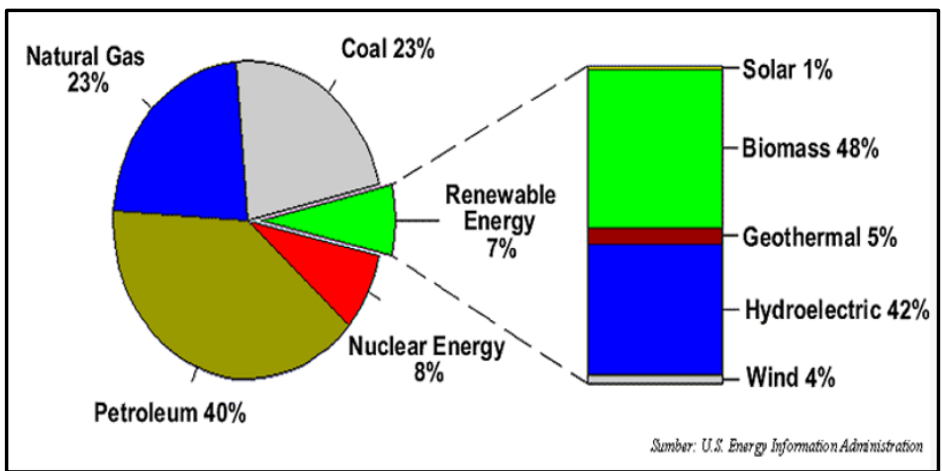

Fig. 1. World energy supply in 2006

Energy supply in the world in 2006 can be seen in Fig. 1 and the potential of Indonesia's renewable energy in 2015 can be seen in Table 1.

Table 1. Indonesia's Renewable Energy Potential in 2015*)

\begin{tabular}{|c|c|c|c|c|}
\hline No & Types of Energy & Potential & Installed Capacity & Utilization \\
\hline 1 & Geothermal & $29.544 \mathrm{MW}$ & $1.438 .5 \mathrm{MW}$ & $4,9 \%$ \\
\hline 2 & Air & $75.091 \mathrm{MW}$ & $4.826,7 \mathrm{MW}$ & $6,4 \%$ \\
\hline
\end{tabular}




\begin{tabular}{|c|c|c|c|c|}
\hline 3 & Mini and Micro Hydro & $19.385 \mathrm{MW}$ & $197,4 \mathrm{MW}$ & $1,0 \%$ \\
\hline 4 & Bioenergy & $32.654 \mathrm{MW}$ & $1.671,0 \mathrm{MW}$ & $5,1 \%$ \\
\hline 5 & Surya & $\begin{array}{c}207.898 \mathrm{MW} \\
(4.80 \mathrm{kWH} / \mathrm{m} 2 / \mathrm{day})\end{array}$ & $78,5 \mathrm{MW}$ & $0,04 \%$ \\
\hline 6 & Wind & $60.647 \mathrm{MW}(3 \mathrm{~mm} / \mathrm{s})$ & $3,1 \mathrm{MW}$ & $0,01 \%$ \\
\hline 7 & Sea & $17.989 \mathrm{MW}$ & $0,3 \mathrm{MW}$ & $0,002 \%$ \\
\hline & Total & $443.208 \mathrm{MW}$ & $8.215,5$ & $1,9 \%$ \\
\hline
\end{tabular}

*) Source of Presidential Regulation 22 of 2017 concerning the National Energy General Plan (RUEN)

Based on Fig. 1 and Table 1 it appears that the use of renewable energy in the world is only around $7 \%$ and for Indonesia its utilization has only reached $2 \%$ of the total potential of renewable energy that exists. The direction of national energy policy includes reducing dependence on fossil fuels, especially petroleum. Utilization of renewable energy is needed for the sustainability of national energy supply and reserves.

Indonesia is located in the equator where every day is passed by the sun, every day there is always sunlight and it turns out the energy potential of solar energy is quite large, which is $4.80 \mathrm{kWh} / \mathrm{m} 2 /$ day. Indonesia is also referred to as a maritime country, because $2 / 3$ of Indonesia's territory is the sea with the longest coastline in the world, which is \pm $80,791.42 \mathrm{Km}$ and is also referred to as an island nation because it has thousands of islands. Such a natural situation is certainly a great potential that must not be wasted, especially for the development of renewable energy, both geothermal, micro-hydro, wind, solar, or especially the energy sourced from the sea which is vast and abundant. One of the alternative renewable energy sources sourced from the sea that is currently not developed in Indonesia is solar ponds, even though Indonesia geographically has enormous potential to develop this technology. There are at least two potential parameters for building a solar pond, first because Indonesia has a tropical climate that has a large amount of sun with intensity and the second because Indonesia is a maritime country surrounded by sea, so the availability of raw water is very abundant. Solar pond is not a new power generation technology. This technology has been developed in several countries including Solar Pond En Boqeq in Israel in 1979, United States of Texas University Solar El Paso Pond in 1983 and at Australia RMIT University Solar Pond in 2000. However, in the history of electricity generation technology in Indonesia, this technology has never been tested and implemented at all. Sources of abundant natural potential in Indonesia are still untouched. In accordance with the RUPTL (Electricity Supply Business Plan) and the National Energy Policy (KEN) it leads to the development of renewable energy. This is in line with the Unhas Strategic Plan on the development of specific Indonesian maritime continents in point 2 (Developing Indonesian Maritime Continent Science-based Science = BMI) which aims to improve the quality and relevance of research, Development of superior research and Network and partnership development in the implementation of specific BMI-based research.

This study focuses on the study of renewable energy using sea water and sunlight as a renewable source of electricity. The long-term goal is to develop renewable energy, which is a solar pool that is environmentally friendly non-fossil fuels, the purpose of which is the use of sea water and sunlight as a source of electricity. The method was the development of a 
laboratory scale prototype solar pond that had been made previously with several improvements to obtain gradient salinity and temperature data in real time and automatically.

\section{Solar Pond technology}

Solar pond is a sea water pool that functions to collect solar thermal energy and the heat energy produced will be converted into electrical energy. This technology is a fundamental technology and is very easy to use with enough land and the right design. The size also varies depending on the needs. Solar pond technology is very well used in areas that have a lot of sunshine and certainly this technology is environmentally friendly and pollution-free.

Basically, water under the hot sun can absorb the sun's heat naturally. When the sun's heat energy enters the sea water, the water will heat up and the hot water part will drop because there is expansion in the water so that hot water will rise to the surface and cooler water will be at the bottom. As a result of contact between hot water and surface air there is heat release by conduction and convection in the hot water so that the heat in the water is wasted, so that the heat in the water is not wasted then salt is added to the water. It is known that hotter water can dissolve salt better than cold water. When water is given salt is heated salt will dissolve easily in water so that hot water that was light will become heavier because the salt solution makes the density of the water becomes heavier and cooler water will rise to the surface because it is lighter.

\subsection{Solar Pond Construction}

A solar pond aimed at collecting and storing energy. Solar pond can operate continuously throughout the year and collect energy from sunlight radiation. Radiation heat can be collected at the bottom of the molars pond and can be used later to produce electrical energy. Schematic Solar pond is shown in Fig. 2. It should be noted that the size of the solar pond depends on the purpose of energy use whether as water heating, drying plants, desalination and electricity. The solar pool can be divided into 3 regions, namely Upper Convective Zone (UZC), Middle Non-Convective Zone (NCZ) and Lower Convective Zone (LCZ) [1].

Upper Convective Zone (UCZ) is located at the top of the solar pool, the temperature in this zone is almost the same as the ambient temperature (environment) and the concentration of salt also approaches clear water. Because contact between the upper layer of the zone and the environment, there is an energy loss due to convection and evaporation. The next zone is the Non-Convection Zone (NCZ) under the Upper Convection Zone. In this zone, the salt concentration changes with the measured depth of the UCZ and NCZ interfaces. Increasing depth increases the salt concentration. The function of this zone is to protect heat convection from the optimum thickness of zone arches and obtain high efficiency from energy storage in the solar pool. The last zone, the Lower Convection Zone (LCZ), is a zone with the highest salt content. Concentrate on this zone uniformly. When the pond receives heat from solar radiation, heat will enter through $\mathrm{UCZ}$ and $\mathrm{NCZ}$ to be stored at the bottom $[5,6]$. 


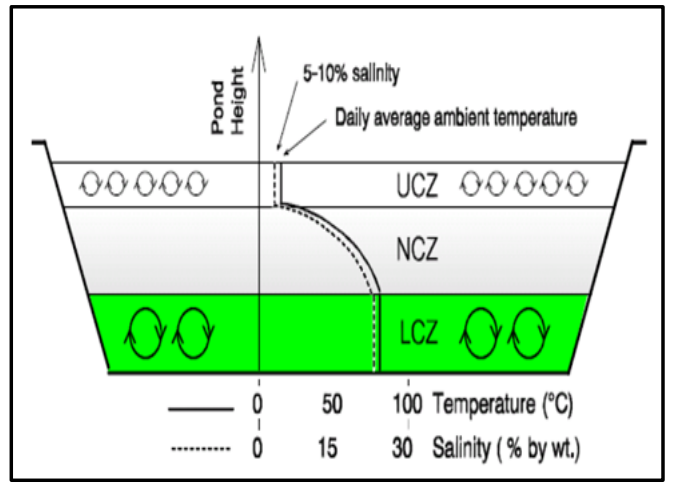

Fig. 2. Schematic of Solar Pond

\subsection{Related Research related}

Research on solar ponds has been carried out previously, among others: Singh (2012) has examined small-scale power plants using low heat content from Solar Pond and Power Plants from Gradient Solar Pond Salinity using thermoelectric generators for renewable energy applications. [7] researches on Power Plants from Solar Pond using a combination of thermosyphon and thermoelectric modules. [8] Technique and calculation of solar pond design in Africa. M. C. Giestasa (2014) modelled solar pond numerically to determine the temperature profile of the solar pond. Liu, [9] analysed the thermal characteristics of trapezoidal solar ponds. [10] simulates an ac supply with a salinity gradient solar pond in Saudi Arabia. [11] increases the efficiency of hot extraction ponds using lateral and heat exchangers. [12] have made a laboratory scale prototype solar pond as an alternative energy source

Research on solar ponds will be one of the solutions for the development of renewable energy sources with the use of abundant sunlight and sea water that will never run out, reduce energy sources from fossil fuels and provide small-scale electricity availability, especially in salt-producing areas and this technology includes clean energy which does not produce global warming.

This research is a development from a previous year research entitled laboratory scale pond in the form of a prototype. It is hoped that this research will be one of the solutions for the development of renewable energy sources with the use of sunlight and abundant sea water that will never run out, reducing use energy sources from fossil fuels and provide small-scale availability of electricity especially in salt-producing regions and this technology includes clean energy that does not produce global warming. This is related to the Unhas research strategic plan.

\subsection{Utilization of Wi-Fi-based Realtime Monitoring}

System For the utilization of a Realtime monitoring system research the method used is data transmission over the internet via a Wi-Fi data network, in this case the tool used is ESP8266. ESP8266 is a SOC (System on Chip) based Wi-Fi module, so we can do ESP8266 direct programs without the need for additional microcontrollers and this module can also play a dual role as an adhoc access point and also client access at the same time. This module is also very low energy with electricity consumption of $140 \mathrm{~mA}$ when operating at a maximum 
speed of $54 \mathrm{mbps}$, and in standby / standby mode is only $15 \mathrm{~mA}$, so the Wi-Fi module is very possible to use batteries as the main energy source that works at $3.3 \mathrm{~V}$ as seen in Fig. 3.

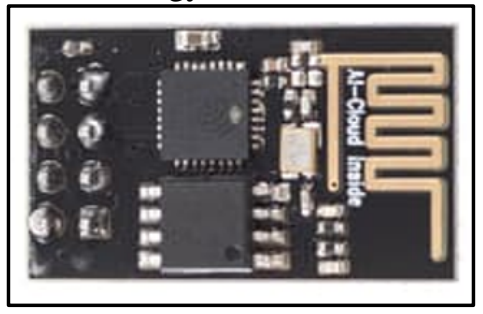

Fig. 3. Wi-Fi ESP8266 module

This module only has limited network access, where this module has a dependency on surrounding Wi-Fi sources as its main source in accessing and sending data in real time to the user. Therefore, in this study real time monitoring systems based on GSM networks were used so that it could use a network of local providers such as Telkomsel, XL, Three, Indosat, etc.

\subsection{GSM-based Realtime}

As explained above to cover the shortcomings of the Wi-Fi-based real time module, additional modules are used in the form of the M590E GSM Module as shown in Fig. 4.

The module works on $900 \mathrm{MHz}$ and $1800 \mathrm{MHz}$ GSM frequencies, where the frequency is used for all networks GSM provider card in Indonesia.

This M590E GSM module can use communication services based on SMS services and GPRS data services; the existence of this SMS service makes it possible for the device to send SMS to the user about the data information needed from the device to the user. GPRS service allows device modules to access TCP / IP internet via GPRS cellular card networks that are used so that it can exchange information data in real time through cyberspace. This module can work at a voltage source of $3.3 \mathrm{~V}-4.5 \mathrm{~V}$ with power consumption at work of $210 \mathrm{~mA}$ and when standby is $2.5 \mathrm{~mA}$, you could say this module is quite energy efficient in its use.

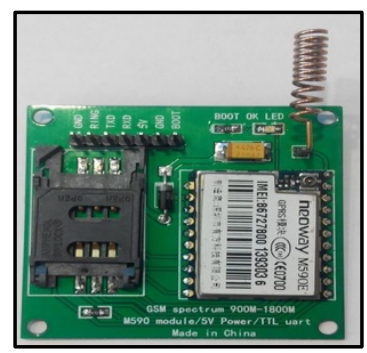

Fig. 4. GSM / GPRS M590E module

\section{Design Proposed Research Methods for Solar Ponds}

In the design of the first solar pond which is prepared is a reservoir of seawater using a reservoir of water which is usually found in water reservoirs in housing, then the shelter is cut at the top so that the sea water surface can receive light the sun as a whole[13, 14]. The stages of this research are aimed at monitoring several types of changes that occur in the 
scope of the research primarily on seawater reservoirs, among others: solar UV intensity, ambient light level, ambient temperature, air humidity, water ph, water bath temperature, and salinity level like water. Stage of research can be seen on Fig.5.

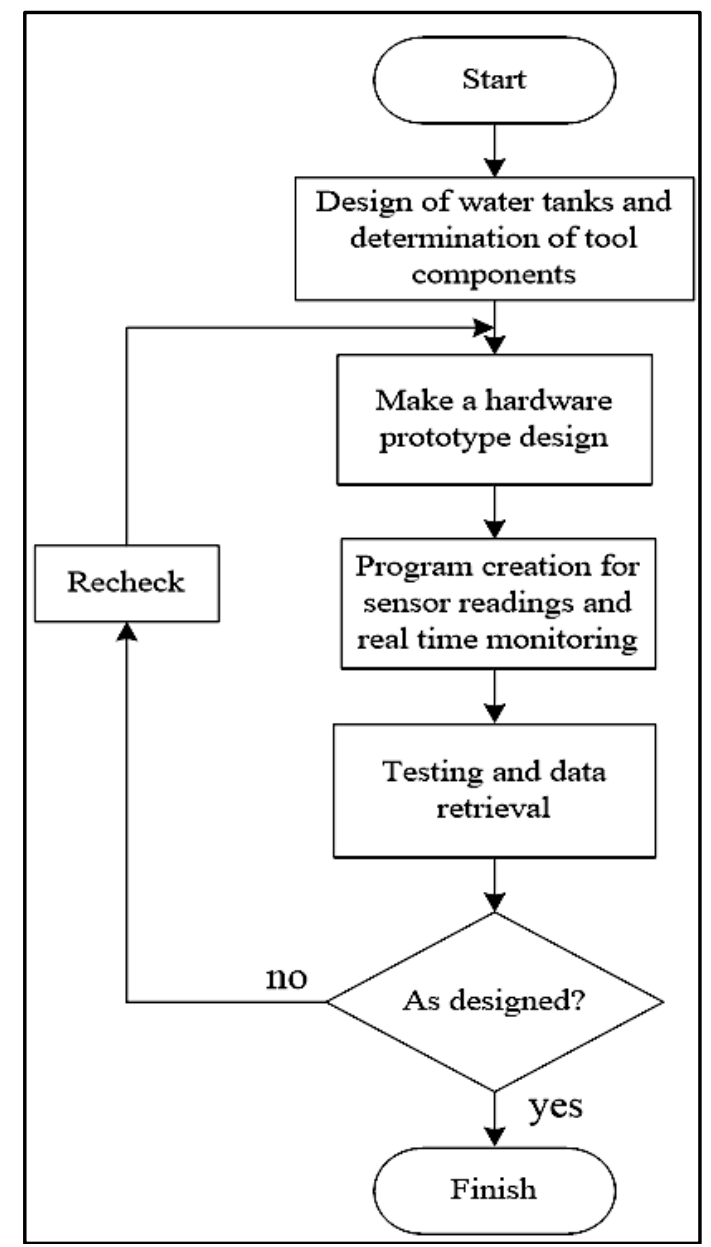

Fig. 5. Stages of Research

To do the data collection, recording and monitoring of the results of research data is needed in real time, recording is done using SD card data logging with the storage of the results of research data into an SD card to be read later. While for real time monitoring using data transmission via SMS and via the internet so that the results of observational data can be seen in real time at that time without any distance restrictions. The block diagram of the research stages can be seen in Figure 5. The next step is to do black staining on the inner base rather than the reservoir, after that the packaging is done using Styrofoam and aluminium foil on the outside which is then covered with tarped rubber to reduce the heat energy that is wasted out of the surrounding environment and then fill with sea water to a full reservoir. The stages can be explained as in the following series of Fig. 5 .

The next design is the design of measurement and monitoring tools for seawater storage that has been made as above. Measuring instruments on seawater storage include several aspects, namely: measurement of solar UV intensity, measurement of sunlight, measurement 
of environmental temperature, measurement of environmental humidity, measurement of $\mathrm{pH}$ of seawater, measurement of sea water temperature, and measurement of salinity of sea water. For complete information can be seen in diagram block Fig. 7 design of the measurement and monitoring process.

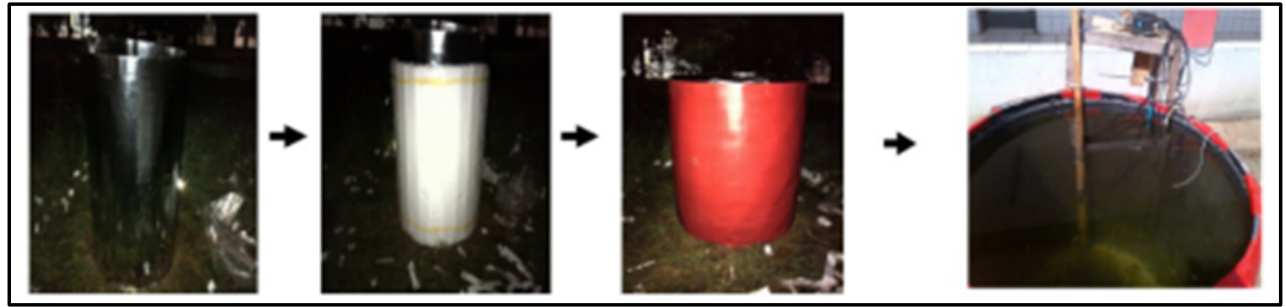

Fig. 6. Planning for seawater storage

The block diagram in Figure 6 describes the overall process in the measurement tool and real time monitoring of the ponds that have been made. It can be seen that the tool first initializes by processing input output on the microcontroller and describes it with the contents of the software in accordance with the program command contents has been given before. Furthermore, processing the readings of sensors includes; air temperature sensors, water temperature, water ph, water salinity, air humidity, sun UV level, ambient light level, and RTC or real time clock readings to find out the time during which the equipment is performing processing. Performed by continuing the reading process if there is an incoming call (miscall) on a device that indicates that there is a request for data at that time.

After reading the entry number, the number is stored and reused as the SMS sending address with the results of reading the sensors at that time. Not only that data transmission is also done via the internet by using a Wi-Fi module by using a nearby Wi-Fi internet source where the tool acts as a client around and sends data on the results of sensor readings in real time. Next, the tool performs updating the status to find out the overall reading process and the process of sending data in real time successfully and sending to the number on the incoming call the results are displayed on the LCD monitor on the device and after completion the tool returns to initialization to re-initialize and so on. Overall, the measurement process and data transmission in real time are controlled by micro controller's which work continuously to read the input sensors for further processing and data transmission processes. We can see this in the following Fig. 7 diagram of the measurement tool and monitoring.

The micro controller used is Arduino Atmega2560, Arduino is based on the AT mega 2560 AVR 8 bit microcontroller which has $256 \mathrm{~kb}$ memory and $8 \mathrm{~kb}$ SRAM and $4 \mathrm{~kb}$ EEPROM, these memories are used for memory to program, process and store temporary data. Atmega2560 has 54 digital pins which can be input or output, they work at a voltage of $5 \mathrm{v}$ on each pin. The Arduino mega2560 is connected to an LCD display with $16 \mathrm{x} 2$ characters which means it has 16 column and 2 lines of characters in appearance. This LCD is connected to Arduino with an 8bit data system with 4 pin connections to access the data bus that will be sent by Arduino to the LCD and RS pin or register select with High condition: to send LCD and Low data: to send instructions on the LCD, and to pin E or enable with Arduino sends a high value or 1 so that the LCD is ready to receive instructions or data.

In this research tool there are 2 kinds of temperature sensors namely water temperature sensors and ambient air temperature sensors or environments, for temperature sensors in this water using DS18B20 type temperature sensors where these sensors are sensors that have water resistance making it possible to measure temperatures at certain depths in a pool of 
water. This DS18B20 sensor is a digital sensor that uses a 1 wire communication or sensor protocol that only uses 1 pin to communicate.

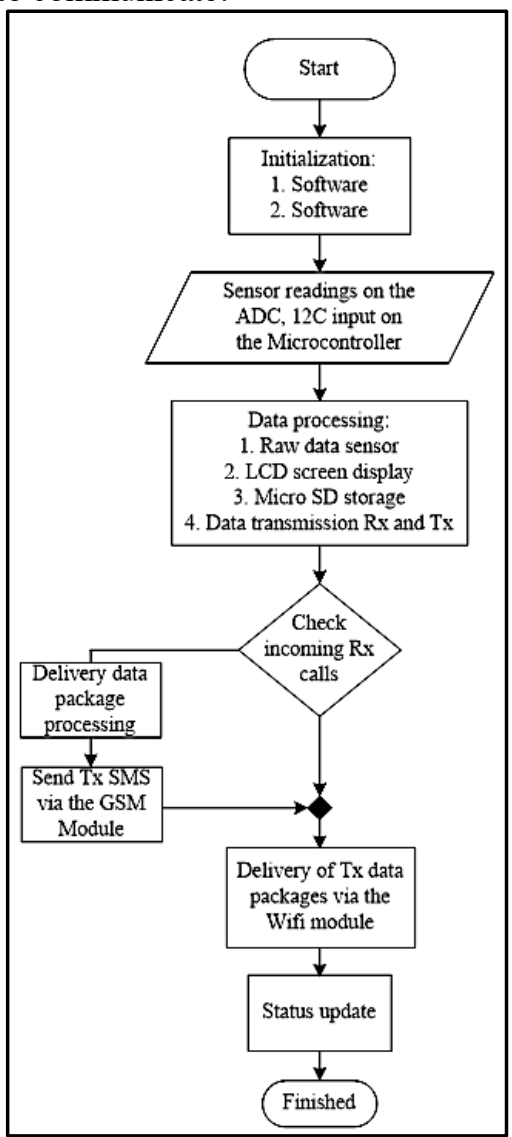

Fig. 7. Design Process Diagram measurement and monitoring

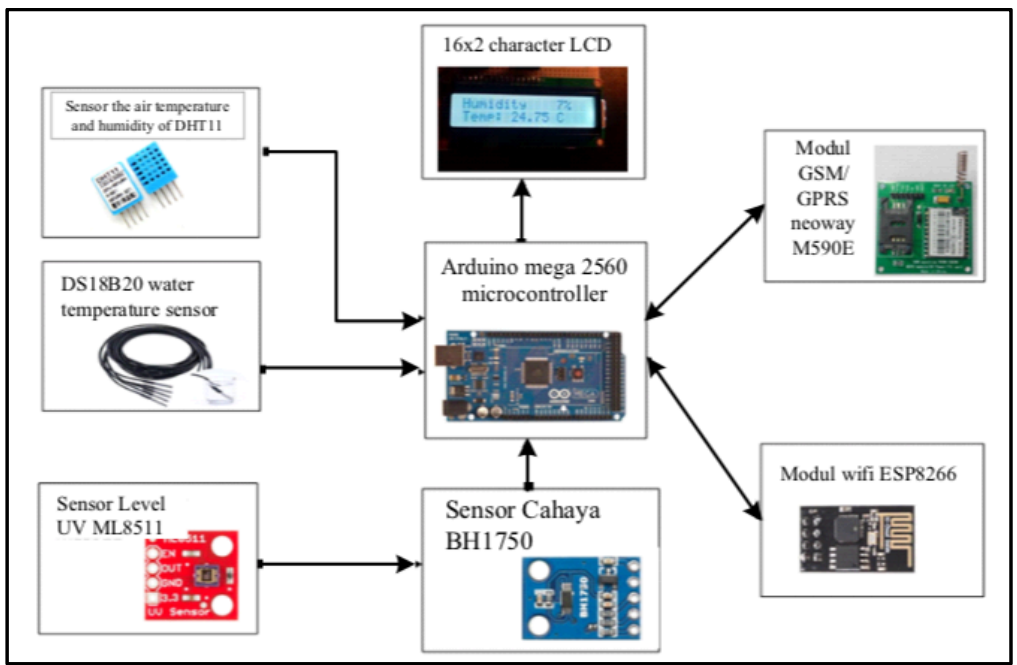

Fig. 8. Diagram of measurement and monitoring tools 
This DS18B20 has 3 pins consisting of 5V supply, ground and input / output data, this sensor can operate at temperatures of $-55^{\circ} \mathrm{C}$ to $125^{\circ} \mathrm{C}$. As for the surrounding air temperature sensor using a DHT11 sensor, where this sensor can also measure the humidity around. This DHT11 sensor is a digital sensor where in its use is connected to the ADC pin on the microcontroller to convert the sensor output voltage value to a value of temperature and humidity.

The ability of this sensor can measure temperatures with a range of $0^{\circ} \mathrm{C}-50^{\circ} \mathrm{C}$ and a humidity measurement range of $20 \%-95 \% \mathrm{RH}$. To find out the intensity value of ultraviolet (UV) and sunlight used 2 sensors, namely the ML8511 sensor to detect UV values in the sun and BH1750 sensor to detect the level of light in the sun. The ML8511 sensor can be used to detect UV values in $280 \mathrm{~nm}$ - 390nm light waves, where light waves are categorized as a spectrum of UVA radiation (tanning light) and UVB (burning of light) in sunlight.

This sensor uses a photodiode that works at $3.3 \mathrm{~V}$ voltage in converting UV values into voltage values so that the reading with the use of a low power of $300 \mu \mathrm{A}$ is connected to the $\mathrm{ADC}$ pin of the microcontroller in its reader. The next sun sensor, the BH1750, can detect the dim light value of a light, whether it's the sun or the lamp in lux units. This sensor is a digital light sensor that has a digital output that is digitally connected to an I2C pin on a microcontroller that can communicate in two directions consisting of $\mathrm{SCl}$ (serial clock) and SDA (serial data) channels that can send digital signals through the clock signal on the microcontroller. Simulation and measurement of temperature and salinity can be seen in Fig. 9.

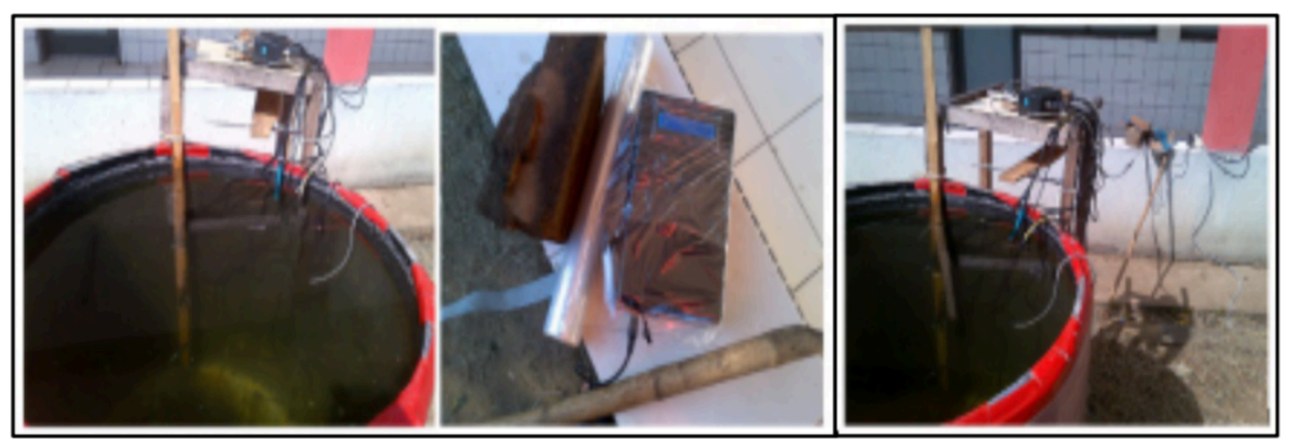

Fig. 9. Simulation and Measurement of salinity and temperature at Solar Pond

\section{Main Results}

System testing of a measurement tool that has been designed aims to determine whether the measurement tool that has been made can work well as expected. This test is carried out in a reservoir that has been filled with seawater in an open place exposed to sunlight. To observe the process of forming a solar pond system at a previously designed sea water reservoir. This test is carried out in a reservoir that has been filled with sea water, which has not been added to salt in other words is still normal. Measurements are carried out at 08.00 to 17.00 for 3 days. The results of measurements of salinity and temperature can be seen in the following graph: 


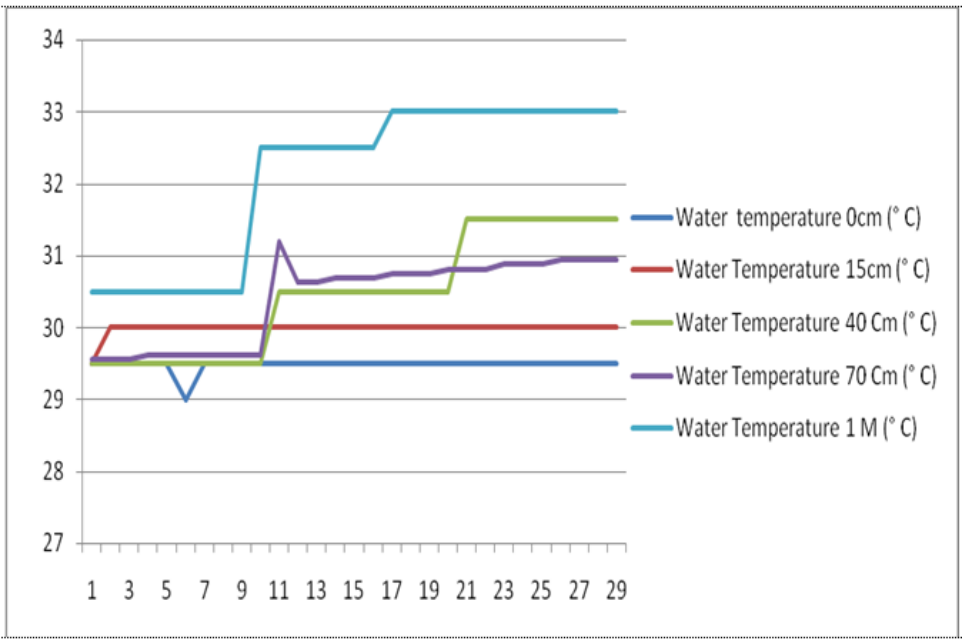

Fig. 10a. Results of first day temperature measurements

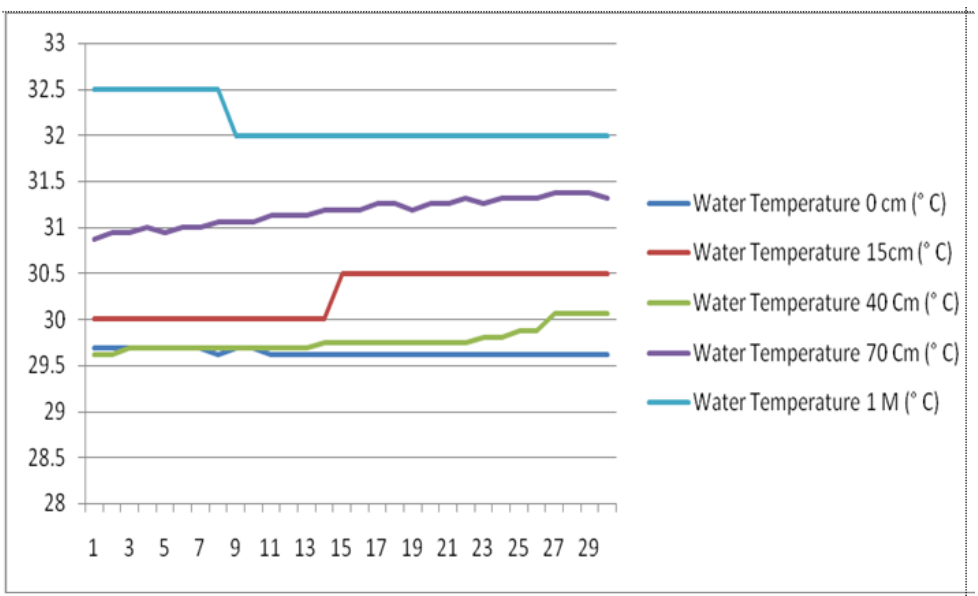

Fig. 10b. Second day temperature measurement results

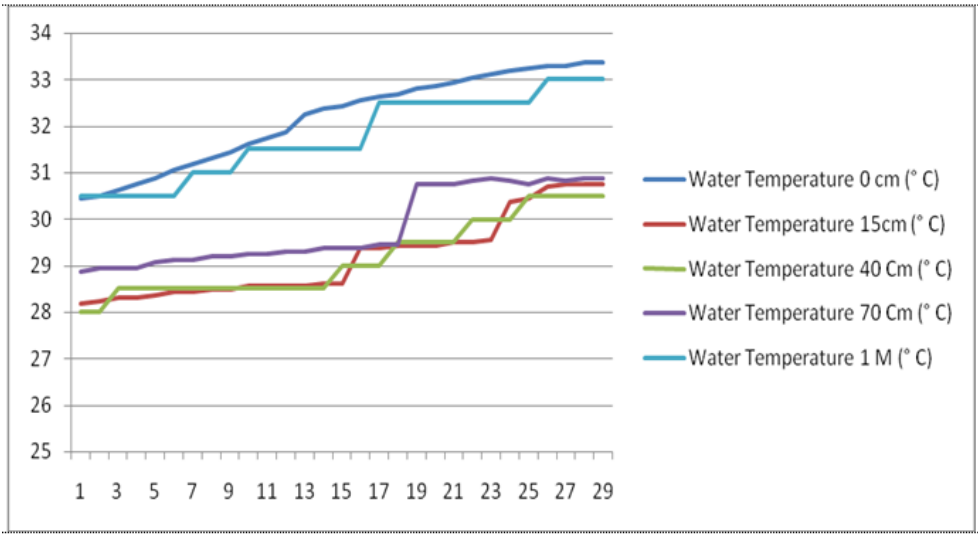

Fig. 10c. Third day temperature measurement results 


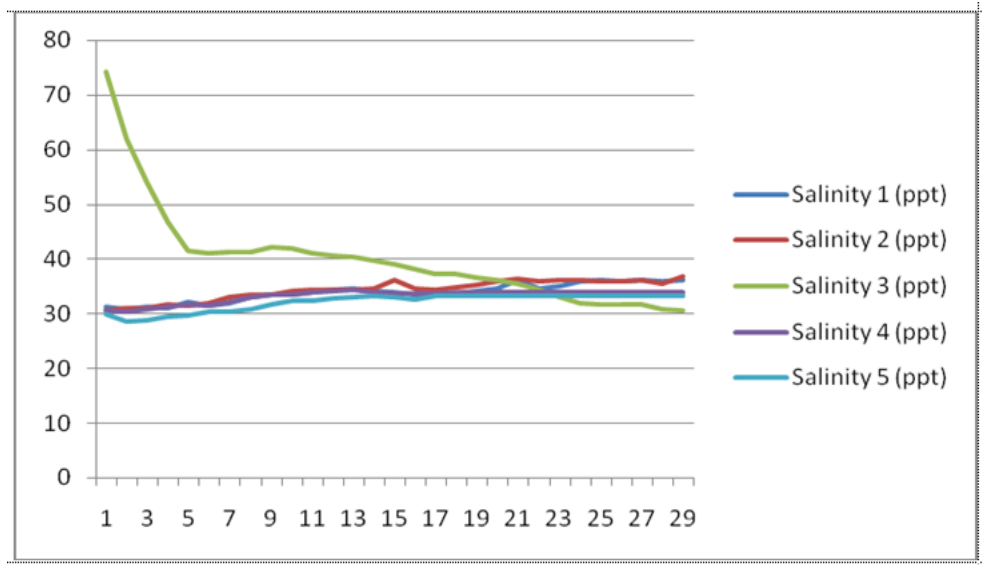

Fig. 11a. First day salinity measurement results

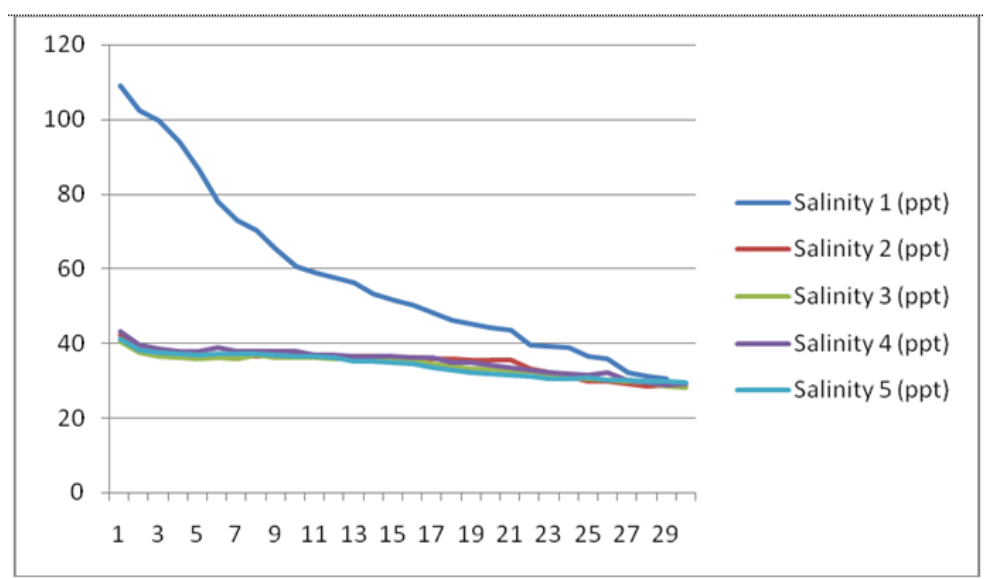

Fig. 11b. Salinity measurement results for the second day

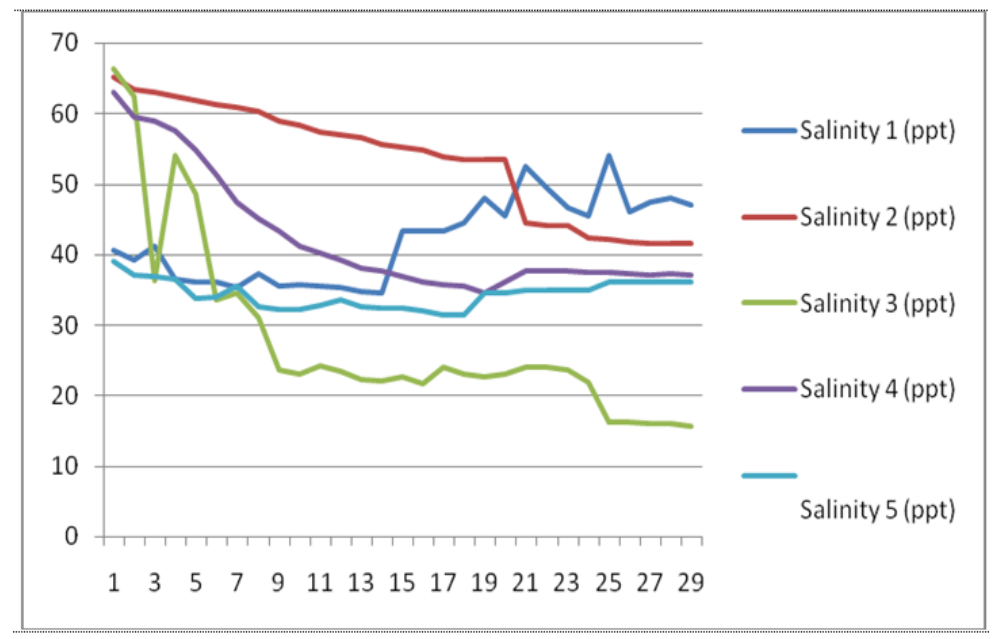

Fig. 11c. Third day salinity measurement results 


\section{Conclusions}

The implementation of a prototype system monitoring real time gradient salinity and complete solar pond temperature have been tested and obtained data accurately. The proposed solar pond makes it easy to get data obtained from solar ponds. Then, the data can be processed according to the time of monitoring and can obtain the right temperature, so that it can be converted into electrical energy. The tested system has obtained data that can be shown from figure $10 \mathrm{a}-10 \mathrm{c}$ until figures $11 \mathrm{a}$ to $11 \mathrm{c}$ which show the results of salinity. Temperature measurement results obtained from $0 \mathrm{~cm}, 15 \mathrm{~cm}, 40 \mathrm{~cm}, 70 \mathrm{~cm}$ and 1 meter in real time.

\section{Acknowledgment}

This work is partially supported by BMIS the authors also gratefully acknowledge the helpful comments and suggestions of the reviewers, which have improved the presentation.

\section{References}

1. Mayasari, F. and R. Dalimi. Vegetable oil-based biodiesel feedstock potential in Indonesia. in 2014 Makassar International Conference on Electrical Engineering and Informatics (MICEEI). 2014.

2. Haroen, Y. Hydro, solar, and wind energy as potential electrical power plant in Indonesia - Past conditions and future prospects. in 2016 3rd International Conference on Information Technology, Computer, and Electrical Engineering (ICITACEE). 2016.

3. Siswanto, A., et al., Stability improvement of wind turbine penetrated using power system stabilizer (PSS) on South Sulawesi transmission system. AIP Conference Proceedings, 2018. 1941(1): p. 020036.

4. Nisworo, S. and D. Pravitasari. Potential of irrigation channel as the new renewable energy sources. in 2017 International Conference on Sustainable Information Engineering and Technology (SIET). 2017.

5. Velmurugan, V. and K. Srithar, Solar stills integrated with a mini solar pond analytical simulation and experimental validation. Desalination, 2007. 216(1): p. 232241.

6. Şencan, A., et al., Different methods for modeling absorption heat transformer powered by solar pond. Energy Conversion and Management, 2007. 48(3): p. 724-735.

7. Tundee, S., N. Srihajong, and S. Charmongkolpradit, Electric Power Generation from Solar Pond Using Combination of Thermosyphon and Thermoelectric Modules. Energy Procedia, 2014. 48: p. 453-463.

8. Egbe, J., Design of Solar Pond calculation and technique in Africa. Vol. 6. 2013. 2232.

9. Liu, H., et al., Experiment and simulation study of a trapezoidal salt gradient solar pond. Solar Energy, 2015. 122: p. 1225-1234.

10. Kanan, S., J. Dewsbury, and G.F. Lane-Serff, Simulation of Solar Air-Conditioning System with Salinity Gradient Solar Pond. Energy Procedia, 2015. 79: p. 746-751.

11. Alcaraz, A., et al., Enhancing the efficiency of solar pond heat extraction by using both lateral and bottom heat exchangers. Solar Energy, 2016. 134: p. 82-94. 
12. dkk;, Z.M., Studi Perbandingan Pengaruh Temperatur Miniatur Matahari dengan Lampu Sorot pada Solar Pond. Proceeding Seminar Nasional Teknik Elektro dan Informatika (SNTEI), 2017: p. p.247-251.

13. Singh, B., et al. Power generation from salinity gradient solar pond using thermoelectric generators for renewable energy application. in 2012 IEEE International Conference on Power and Energy (PECon). 2012.

14. Hull, J.R., et al., Dependence of ground heat loss upon solar pond size and perimeter insulation calculated and experimental results. Solar Energy, 1984. 33(1): p. 25-33. 